\title{
BMJ Open Prevalence and risk factors of MRSA colonisations: a cross-sectional study among personnel in outpatient care settings in Hamburg, Germany
}

Claudia Peters, ${ }^{1}$ Olaf Kleinmüller, ${ }^{1}$ Albert Nienhaus, ${ }^{1,2}$ Anja Schablon ${ }^{1}$

To cite: Peters C, Kleinmüller 0 , Nienhaus A, et al. Prevalence and risk factors of MRSA colonisations: a cross-sectional study among personnel in outpatient care settings in Hamburg, Germany. BMJ Open 2018;8:e021204. doi:10.1136/ bmjopen-2017-021204

- Prepublication history for this paper is available online. To view these files, please visit the journal online (http://dx.doi. org/10.1136/bmjopen-2017021204).

Received 15 December 2017

Revised 28 May 2018

Accepted 31 May 2018

Check for updates

(C) Author(s) (or their employer(s)) 2018. Re-use permitted under CC BY-NC. No commercial re-use. See rights and permissions. Published by BMJ.

${ }^{1}$ Institute for Health Services Research in Dermatology and Nursing, University Medical Centre Hamburg-Eppendorf, Hamburg, Germany

${ }^{2}$ Department of Occupational Medicine, Public Health and Hazardous Substances, Statutory Accident Insurance and Prevention in the Health and Welfare Services, Hamburg, Germany

Correspondence to

Dr Claudia Peters:

c.peters@uke.de

\section{ABSTRACT}

Objectives Healthcare workers frequently come into contact with infected individuals and are at a greater risk of infection than the general population due to their occupation. Multidrug-resistant organisms (MDR0s) also pose a significant challenge for personnel and medical facilities. Currently, little is known about the occupational risk of methicillin-resistant Staphylococcus aureus (MRSA) in outpatient care settings. Therefore, a cross-sectional study was conducted in Hamburg to investigate MRSA colonisation among outpatient nursing staff.

Methods MRSA screening with nasal swabs was carried out, the known risk factors for colonisation were determined and information on infection control was inquired. Where tests were positive, a control swab was taken; if this confirmed a positive result, decolonisation was offered. A molecular biological examination of the MRSA samples was performed. The occupational MRSA exposure and risk factors were compared with the situation for personnel in inpatient geriatric care. Results A total of 39 outpatient services participated in the study and 579 employees were tested. The MRSA prevalence was $1.2 \%$ in all and $1.7 \%$ in nursing staff. Most of the employees that tested positive had close or known contact with MRSA patients. Health personnel frequently reported personal protective measures and their application. Compared with inpatient care staff, outpatient staff were older and had worked in their profession for a longer time.

Conclusion This study marks the first time that data has been made available on the occupational MRSA risk of outpatient care personnel in Hamburg. The MRSA prevalence is low and provides a good basis for describing the MRSA risk of occupational exposure by health personnel in outpatient care.

\section{INTRODUCTION}

Healthcare workers frequently come into contact with infected individuals and are at a greater risk of infection than the general population due to their occupational activities. Multidrug-resistant organisms (MDROs) are increasingly becoming a public health problem. Methicillin-resistant Staphylococcus aureus (MRSA), which is prevalent worldwide,

\section{Strengths and limitations of this study}

- First report of methicillin-resistant Staphylococcus aureus (MRSA) prevalence in health personnel in outpatient care in Germany on a large scale.

- Epidemic strains of detected MRSA colonisations are provided by genotyping.

- Point prevalence investigation did not allow any differentiation between transient and persistent carriage.

is the best known MDRO. This pathogen also poses a significant challenge for employees in various medical settings.

An MRSA prevalence of $0.7 \%$ was found for the general population in Germany. ${ }^{1}$ Data on the frequency of MRSA colonisation among health personnel in non-outbreak scenarios in Europe and in the USA showed prevalence rates of between $0.2 \%$ and $15 \%^{2}$ and average prevalence rates of $4.6 \%{ }^{3}$ and $5 \% .^{4}$ For Germany, studies of employees at medical facilities revealed MRSA colonisation rates of $0.4 \%-4.5 \% .^{5}$

In 2015, 2.9 million people were in need of care in Germany. Nearly three-quarters of them were cared for in their home, of which $66 \%$ were cared for by relatives and outpatient care services or solely by outpatient care services. In the same year, 356000 people were employed in outpatient care in Germany. The majority of employees were women $(87 \%)$, worked part-time and nearly $40 \%$ were aged 50 and older. ${ }^{6}$ According to the population trend for Germany, the number of people in need of care is expected to rise steadily, reaching 3.4 million by $2030 .^{7}$ An increasing number of patients are being discharged early from hospital, who then require either outpatient or inpatient care. ${ }^{8}$ As a result, the need for care on an outpatient basis will also continue to grow. 
Little is currently known about the occupational exposure to MRSA among nursing staff in outpatient care settings. Against this backdrop, a study was performed in which the point prevalence of MRSA colonisations among employees in outpatient care facilities was investigated. Occupational exposure and known risk factors were compared with the situation of personnel in inpatient geriatric care settings, based on an earlier study conducted in Hamburg. ${ }^{9}$

\section{METHODS}

\section{Study population}

The cross-sectional study of employees in outpatient care facilities in Hamburg was conducted from June 2015 to March 2016. A total of 403 facilities for outpatient geriatric and/or nursing care were contacted. The MRSA screening was planned to take place onsite at the facilities. In addition, screening appointments were offered at the study centre. All outpatient services personnel were invited to participate. An age range of 18-65 years was set as an inclusion criterion. The screening procedure was anonymised. For the dissemination of the study results to the participants, an identification code was issued which was not linked to any identifying data. The code made it possible to transmit the results of the laboratory test to the participants.

Swabs from the nasal vestibules of employees were taken for the purpose of screening. Potential risk factors for MRSA colonisation were identified using a questionnaire. Occupational risk factors such as the nature and duration of their work, contact with MRSA patients in a nursing capacity and influential factors such as taking a course of antibiotics, their own hospital stays and contact with animals were explored alongside sociodemographic data. In addition, questions about infection control were asked.

Where MRSA findings were positive, the employees were first given the option of a control swab. If the result was still positive, a non-antibiotic decolonisation kit was provided, consisting of oral, nasal and hand disinfectant and antimicrobial hair and body wash. A further control swab was offered to check whether the decolonisation efforts had been successful.

Results of a previous study were used for the comparison of occupational risks for personnel in outpatient care and inpatient geriatric care. The MRSA screening was performed from 2014 to 2015 in 19 geriatric care facilities in Hamburg and 759 employees were tested. Further details of the study were described by Peters $e t$ $a .^{9}$

The study was conducted in accordance with the requirements of data protection legislation.

\section{Patient and public involvement}

Patients and public were not involved in this study.

\section{Microbiological methods}

Cotton wool swabs were used for the nasal swab examinations. The swab sample was taken by swabbing both anterior nares in a rotating motion for around $5 \mathrm{~s}$ and was then sealed in a transport container. In the laboratory, the swab was first streaked on an MRSA-selective plate (Biomerieux) and then put into a Brain Heart Infusion enrichment broth (Becton Dickinson). The plate and broth were incubated at $37^{\circ} \mathrm{C}$ in an ambient atmosphere. The plate was inspected after 24 hours and 48 hours of incubation. Suspicious colonies were further characterised by matrix-assisted laser desorption ionization-time of flight mass spectrometry (Bruker Daltonics, MALDI Biotyper) either directly from the MRSA-selective plate when present as a pure culture or after isolation on CNA agar (Becton Dickinson). The presence of PBP2A was confirmed by an immunochromatographic assay (Alere, PBP2a SA test). After 24 hours of incubation, the enrichment broth was plated on an MRSA-selective plate, which was then incubated for another 48 hours, with inspection after 24 and 48 hours. For positive samples, $S$. aureus protein A ( $s p a)$ typing was performed. PCR amplification of the spa gene was performed with the primers $5^{\prime}$-TAA AGA CGA TCC TTC GGT GAG C-3' and 5'-CAG CAG TAG TGC CGT TTG CTT-3' using the Hot StartTaq Master Mix (Qiagen).${ }^{10}$ Sequencing of the PCR product was carried out with the BigDye Terminator v3.1 (ThermoFisher) reagent. The sequencing reaction was then purified on Sephadex G-50 DNA Grade (ThermoFisher) columns and subsequently analysed in the ABI 3130xl Genetic Analyser. Resulting sequence data were interpreted with the Ridom tool (http://www.spaserver.ridom.de/).

The univariate analyses were performed using $\mathrm{X}^{2}$ tests based on Pearson, or where cell frequency was low, using Fisher's exact test. For the multivariate analysis, logistic regression was used. The analyses were performed using IBM SPSS Statistics V.23.

\section{RESULTS}

A total of 39 (9.7\%) outpatient care facilities participated in the study (table 1). They mostly provided basic care and treatment, while four facilities were intensive care services (multiple answers possible). The size of the care services ranged from 6 to 170 employees per facility; the median was 32 employees. The number of patients who received care from the individual services was between 8 and 280. Care services were provided by 26 employees in median per facility.

\section{Health personnel}

Five hundred and seventy-nine employees participated in the study. The overall participation rate was $40.5 \%$; in the individual facilities, the response rate varied between $8 \%$ and $81 \%$. The median age of the employees was 46 and one-third were over 50. Most of the participants were female (table 1). Three out of four employees were mainly entrusted with patient care. Of these, $64 \%$ said they 
Table 1 Characteristics of the outpatient care facilities $(n=39)$ and employees $(n=579)$

\begin{tabular}{lll}
\hline Outpatient facilities $^{*}$ & & \\
$\begin{array}{c}\text { Type of service } \\
\text { provided } \dagger\end{array}$ & Basic care & $30(76.9 \%)$ \\
& Treatment care & $31(79.5 \%)$ \\
& Intensive care & $4(10.3 \%)$ \\
Number of & Range & $8-280$ \\
patients & Mean/SD & $99.0 / 65.6$ \\
& Median & 86 \\
\hline
\end{tabular}

$\begin{array}{cll}\text { Total personnel } & \text { Range } & 6-170 \\ & \text { Mean/SD } & 41.1 / 5.7 \\ & \text { Median } & 31.5 \\ \text { Nursing staff } & \text { Range } & 5-163 \\ & \text { Mean/SD } & 34.3 / 31.1 \\ & \text { Median } & 25.5 \\ \text { Health personnel } & & \mathrm{n}(\%) \\ \text { Age in years } & <30 & 76(13.1) \\ & 30-39 & 114(19.7) \\ & 40-49 & 158(27.3) \\ & 50-59 & 174(30.1) \\ & >60 & 47(8.1) \\ & \text { Unknown } & 10(1.7)\end{array}$

\begin{tabular}{lll} 
Sex & Female & $460(79.4)$ \\
& Male & $106(18.3)$ \\
& Unknown & $13(2.2)$ \\
\hline $\begin{array}{l}\text { Mainly nursing } \\
\text { activities }\end{array}$ & $423(73.1)$ \\
$\begin{array}{l}\text { Care } \\
\text { predominantly } \\
\text { provided† }\end{array}$ & Basic care & $368(63.6)$ \\
Level of training & Treatment care & $313(54.1)$ \\
& Geriatric nurse & $137(23.7)$ \\
& Care assistant/ & $110(19.0)$ \\
& auxiliary nurse & \\
& General nurse & $167(28.8)$ \\
& Without nursing & $127(21.9)$ \\
& qualification & \\
& Other/unknown & $38(6.6)$ \\
\hline Time spent in & $\leqq 10 y e a r s$ & $308(53.2)$ \\
outpatient care & $>10 y e a r s$ & $259(44.7)$ \\
& Unknown & $12(2.1)$ \\
\hline
\end{tabular}

${ }^{*}$ Not responded $n=4$ facilities.

†Multiple answers possible.

performed basic care, including personal hygiene and assistance with excretion and nutrition, $54 \%$ dealt with treatment-related activities such as changing dressings, injections and drug administration, and 20\% provided intensive care involving ventilation treatment, feeding tubes and port/catheter care (multiple answers possible). In terms of professional background, 29\% were qualified general nurses, $24 \%$ were trained geriatric nurses and $19 \%$ had received training as nursing assistants. Twenty-two per cent did not have any nursing qualifications; these included social workers, housekeeping staff, office workers and medical assistants. Fifty-three per cent of the personnel had been working in outpatient care for less than 10 years. No statistically significant differences showed in the comparison of persons who tested positive for MRSA with those who tested negative.

\section{MRSA}

A total of seven employees tested positive for MRSA during screening, putting the prevalence at 1.2\% (95\% CI 0.5 to 2.5 ). These employees were all involved in care activities, resulting in an MRSA colonisation rate among nursing staff of $1.7 \%$ (95\% CI 0.7 to 3.4 ). In the 4 weeks prior to screening, $77 \%$ of all personnel and $93 \%$ of the nursing staff had close contact with patients requiring care with activities like personal hygiene, mobilisation or dressing changes. Known contact with patients infected with a MDRO was reported by $52 \%$ of all employees and $61 \%$ of the nursing staff. Five MRSA carriers reported MDRO patient contact and another six even close contact. In terms of personal risk factors, one-quarter of the respondents said they had used antibiotics in the last 6 months. Hospitalisation or a surgical procedure, chronic respiratory illnesses or skin conditions and home care of relatives were mentioned less frequently. Since the multivariate analysis on the risk of MRSA colonisation did not lead to any statistically significant results, this representation is not included.

The offer for a control swab was taken up by all seven subjects who tested positive, resulting in six still positive MRSA findings. The participants who tested positive after the control swab underwent decolonisation treatment, which was not successful for four employees. These employees were referred to the responsible occupational physician.

The genotyping of MRSA samples showed as a whole five different epidemic strains: commonly occurring (t032, t005) and less prevalent (t379, t613, t10535) in Germany. The spa type t10535 was found three times in two facilities, other strains were only analysed in single employees in individual facilities.

\section{Infection control}

Questions concerning health protection in outpatient care were directed at persons in charge at the facilities (mainly nursing management). They first addressed the sharing of information regarding MDROs/MRSA when transferring patients (table 2). The information from hospitals about colonisation or infection was transmitted in most cases; however, in $10 \%$ of the facilities, this information was not shared. On the other hand, 39\% of the facilities reported receiving information from the primary care physician (yes/mostly), whereas $46 \%$ did not receive this information. The most frequent difficulties were reported for the communication with primary 
Table 2 Infection control regarding MDROs for facilities $(n=39)$ and all employees $(n=579)$ compared with nursing staff $(n=423)$

\begin{tabular}{|c|c|c|c|}
\hline Outpatient facilities* & & $\mathbf{N}(\%)$ & \\
\hline \multirow{3}{*}{ MDROs information from hospitals } & Yes & $11(28.2)$ & \\
\hline & No & 4 (10.3) & \\
\hline & Unknown & $4(10.3)$ & \\
\hline \multirow[t]{3}{*}{ MDROs information from general practitioners } & Yes & $5(12.8)$ & \\
\hline & Mostly & $10(25.6)$ & \\
\hline & Unknown & $6(15.4)$ & \\
\hline \multirow[t]{3}{*}{ Problems in communication with $†$} & General practitioners & $25(64.1)$ & \\
\hline & Hospitals & $22(56.4)$ & \\
\hline & Relatives & $15(38.5)$ & \\
\hline Instructions at work on MRSA/MDROs & $534(92.2)$ & 408 (96.5) & $<0.01$ \\
\hline Protective clothing provided by employer & $526(90.8)$ & $404(95.5)$ & $<0.01$ \\
\hline Wearing work clothes & $216(37.3)$ & $189(44.7)$ & 0.02 \\
\hline \multicolumn{4}{|l|}{ Hand disinfection† } \\
\hline When starting work & $459(79.3)$ & $366(86.5)$ & $<0.01$ \\
\hline After contamination & 407 (70.3) & $330(78.0)$ & $<0.01$ \\
\hline After patient contact & 515 (88.9) & $400(94.6)$ & $<0.01$ \\
\hline When finished working & $469(81.0)$ & $365(86.3)$ & 0.03 \\
\hline Never & $11(1.9)$ & $0(0.0)$ & \\
\hline
\end{tabular}

${ }^{*}$ Not responded $\mathrm{n}=4$ facilities.

†Multiple answers possible.

MDRO, multidrug-resistant organisms; MRSA, methicillin-resistant Staphylococcus aureus; np, nursing personnel.

care physicians, hospitals and family members (multiple answers possible). This mainly applied to missing, insufficient or delayed information regarding a positive MRSA result or a decolonisation treatment of the patient. In addition, it was repeatedly reported that this information is often only mentioned in the physician's letter and never reaches the nursing staff.

The employees were also asked about infection control at their workplace and reported that virtually everywhere work instructions on how to deal with multiresistant pathogens were available and protective clothing was provided by the employer. The wearing of work clothes was reported by $37 \%$ of all employees and $45 \%$ of the nursing staff. The majority of staff carried out hand hygiene; it was reported more often by the nursing staff than by personnel as a whole.

\section{Comparison of outpatient and inpatient geriatric care}

Table 3 compares the characteristics and risk factors for employees in outpatient and inpatient geriatric care settings in Hamburg. It shows that the outpatient care employees in the study were older, that a higher proportion had worked in outpatient care for more than 10 years and $73 \%$ (versus $62 \%$ ) had carried out nursing activities in the inpatient sector. Most of the outpatient employees came from the nursing profession (29\%), followed by geriatric care $(24 \%)$. In inpatient settings, 32\% were trained geriatric nurses and $8 \%$ were qualified general nurses. Other significant differences can be seen at a personal level with regard to the use of antibiotics, caring for relatives and contact with animals.

\section{DISCUSSION}

The current study marks the first time that data on the occupational risk of MRSA in employees of outpatient care facilities in Hamburg could be made available. The MRSA prevalence is low and at $1.2 \%$; it is below the colonisation rate of $1.6 \%$ found among staff of geriatric nursing homes in Hamburg. ${ }^{9}$ Compared with other studies of personnel in medical facilities in Germany, the results are on the lower end of the spectrum. ${ }^{5}$ Studies on the frequency of MRSA in outpatient care have mainly focused on patients. They report MRSA colonisation rates of $3.7 \%,{ }^{11} 4.7 \%{ }^{12}$ and $2.1 \%{ }^{13}$ for Germany. An American study $^{14}$ investigated paediatric healthcare personnel in different outpatient settings. The survey of 227 paediatric 
Table 3 Comparison of outpatient $(n=579)$ and inpatient $(n=759)$ geriatric care staff who underwent methicillin-resistant Staphylococcus aureus (MRSA) screening in Hamburg

\begin{tabular}{|c|c|c|c|}
\hline Variable & $\mathbf{N}_{\text {outpatient }}$ & $\mathbf{N}_{\text {inpatient }}$ & $P$ values \\
\hline \multicolumn{4}{|l|}{ Age in years } \\
\hline Mean/SD & $44.5 / 11.8$ & $41.8 / 12.4$ & $<0.01$ \\
\hline \multirow[t]{2}{*}{ Median } & 46 & 43 & \\
\hline & $\mathrm{n}(\%)$ & $\mathrm{n}(\%)$ & \\
\hline Positive MRSA results & $7(1.2)$ & $12(1.6)$ & 0.65 \\
\hline \multicolumn{4}{|c|}{ Time spent in outpatient or inpatient care } \\
\hline$<1$ year & $76(13.1)$ & $79(10.4)$ & $<0.01$ \\
\hline $1-5$ years & $152(26.3)$ & $157(20.7)$ & \\
\hline $6-10$ years & $80(13.8)$ & $147(19.4)$ & \\
\hline$>10$ years & $259(44.7)$ & $248(32.6)$ & \\
\hline Unknown & $12(2.1)$ & $128(16.9)$ & \\
\hline \multicolumn{4}{|l|}{ Level of training } \\
\hline Geriatric nurse & $137(23.7)$ & $241(31.8)$ & $<0.01$ \\
\hline Care assistant/auxiliary nurse & $110(19.0)$ & $110(14.5)$ & \\
\hline General nurse & $167(28.8)$ & $58(7.6)$ & \\
\hline Without nursing qualification & $127(21.9)$ & $78(10.3)$ & \\
\hline Other/unknown & $38(6.6)$ & $272(35.8)$ & \\
\hline Nursing activities & $423(73.1)$ & $471(62.1)$ & $<0.01$ \\
\hline Close contact with patients & $447(77.2)$ & $553(72.9)$ & 0.075 \\
\hline Use of antibiotics & $140(24.2)$ & $261(34.4)$ & $<0.01$ \\
\hline Care of relatives & $60(10.4)$ & $38(5.0)$ & $<0.01$ \\
\hline Contact with animals & $343(59.2)$ & $396(52.2)$ & $<0.01$ \\
\hline
\end{tabular}

healthcare workers in outpatient settings revealed a prevalence of $3.1 \%$. In terms of risk factors, only prior surgery was shown to be associated with MRSA colonisation. In our study, however, no correlation with the known risk factors was found for the entire study population. It was only after differentiation of the nursing staff that close contact, MDRO contact and infection control measures demonstrated statistical significance. These differences can be explained by the fact that all MRSA colonisations were identified in the nursing area - due to their profession, nursing staff have the closest contact with patients and are better informed about protective measures than care support staff and therapists.

\section{Infection control}

Other studies dealt with infection control due to the organisational characteristics of outpatient care. A study of the public health service in Bavaria ${ }^{15}$ showed that smaller facilities in particular (with fewer than 10 patients) achieved poor results in infection control, knowledge about relevant recommendations for action and the availability of work aids. In the large facilities, on the other hand, personnel conditions were less favourable.

Outpatient care poses a particular challenge for infection control due to the fact that it is provided in the patient's home environment. In this scenario as well, however, the recommendations emphasise the need for basic hygiene, such as hand hygiene, barrier measures and surface disinfection. ${ }^{5}$

What stands out in the analysis of the study results is the insufficient communication between the various actors in the healthcare sector in some cases. Hospitals often do not share information about a positive MDRO test result with the outpatient facilities or there is no information regarding decolonisation/control swabs. Primary care physicians also rarely make the nursing staff aware of such findings. Moreover, MRSA carriers themselves are not always and sufficiently informed and experience stigmatisation at times. ${ }^{16}$ In terms of infection prevention, however, sharing information about MDROs is important for everyone concerned, in order to ensure optimal patient care and employee protection. Similar results regarding risk communication were also obtained by other authors, ${ }^{17}$ and these problems were also reported with regard to inpatient geriatric care. ${ }^{18}$

\section{Comparison of outpatient and inpatient geriatric care}

In comparing the employees in geriatric outpatient and inpatient settings in Hamburg, differences can be seen. The participants from the outpatient setting were older and had worked in their profession longer, came predominantly from the nursing and geriatric care professions 
and took care of family members at home twice as often. A more self-determined work environment and flexible hours may be an advantage in outpatient care. The better compatibility of family and career for women returning to work after having children also seems to be a long-term alternative for nursing staff compared with a hospital setting.

\section{Limitations}

The study encountered problems in terms of willingness to participate. This was especially evident when recruiting facilities. Despite repeated contact, motivating those in charge to participate was difficult. We can only speculate about the reasons. The reluctance of employers to agree to the MRSA screening is mainly attributable to the fear of numerous positive results. The worry that employees who test positive for MRSA would increasingly take sick leave underscores the problem of the pre-existing shortage of personnel in this sector. In addition, the fear of reputational damage due to a high MRSA prevalence as well as the greater organisational effort required may also be partly responsible for the refusal to participate. It is therefore likely that the results were distorted due to a selection bias. Coupled with low participation rates, an underestimation of the actual MRSA risk cannot be ruled out.

In our study, only point prevalence was investigated; hence, a differentiation between transient and persistent MRSA carriage was not possible. For a complete depiction of the occupational exposition, data are missing of the patients' MRSA prevalence, their MRSA genetic strains and of transmission routes. Statements on the success of decolonisation are unreliable due to the small number of cases.

\section{CONCLUSION}

This study made it possible to determine the rate of MRSA among outpatient care staff in Hamburg for the first time and it describes the occupational risk of exposure to health personnel in outpatient care. The MRSA prevalence is low but all MRSA colonisations were found in nursing personnel. Known risk factors did not show any correlation with MRSA colonisation. Achievements could be gained by improving information and communication of the infection status of the patient. A good infection control at the facilities is highly recommendable and the employees should acquire in-depth knowledge of infection prevention to improve the compliance with basic hygiene measures such as hand disinfection and personal protective measures.

Acknowledgements We would like to thank all participants for their collaboration. Contributors CP was involved in designing the study, made the statistical analysis and interpretation of the data and drafted the manuscript. OK participated in the design of the study, performed data collection and has been involved in the drafting of the manuscript. AN participated in the design of the study and helped to draft the manuscript. AS participated in the design of the study and has been involved in the drafting of the manuscript. All authors read and approved the final version of the manuscript.

Funding The authors have not declared a specific grant for this research from any funding agency in the public, commercial or not-for-profit sectors.

Competing interests None declared.

Patient consent Not required.

Ethics approval The Ethics Committee of the General Medical Council (WF-019/15) for the city of Hamburg.

Provenance and peer review Not commissioned; externally peer reviewed.

Data sharing statement No additional data sharing available.

Open access This is an open access article distributed in accordance with the Creative Commons Attribution Non Commercial (CC BY-NC 4.0) license, which permits others to distribute, remix, adapt, build upon this work non-commercially, and license their derivative works on different terms, provided the original work is properly cited, appropriate credit is given, any changes made indicated, and the use is non-commercial. See: http://creativecommons.org/licenses/by-nc/4.0/.

\section{REFERENCES}

1. Köck R, Werner P, Friedrich AW, et al. Persistence of nasal colonization with human pathogenic bacteria and associated antimicrobial resistance in the German general population. New Microbes New Infect 2016;9:24-34.

2. Dulon M, Peters $C$, Schablon A, et al. MRSA carriage among healthcare workers in non-outbreak settings in Europe and the United States: a systematic review. BMC Infect Dis 2014;14:363.

3. Albrich WC, Harbarth S. Health-care workers: source, vector, or victim of MRSA? Lancet Infect Dis 2008;8:289-301.

4. Hawkins G, Stewart S, Blatchford O, et al. Should healthcare workers be screened routinely for meticillin-resistant Staphylococcus aureus? A review of the evidence. J Hosp Infect 2011;77:285-9.

5. Empfehlung der Kommission für Krankenhaushygiene und Infektionsprävention (KRINKO) beim Robert KochInstitut. Empfehlungen zur Prävention und Kontrolle von Methicillin-resistenten Staphylococcus aureus-Stämmen (MRSA) in medizinischen und pflegerischen Einrichtungen. Bundesgesundheitsblatt Gesundheitsforschung Gesundheitsschutz 2014;57:695-732.

6. Statistisches Bundesamt. Pflegestatistik. Pflege im Rahmen der Pflegeversicherung, Deutschlandergebnisse. 2015;2017 https://www. destatis.de/DE/Publikationen/Thematisch/Gesundheit/Pflege/Pfle geDeutschlandergebnisse.html.

7. Statistisches Bundesamt. Demografischer Wandel in Deutschland. Auswirkungen auf Krankenhausbehandlungen und Pflegebedürftige im Bund und in den Ländern. 2010 https://www.destatis.de/DE/ Publikationen/Thematisch/Bevoelkerung/DemografischerWandel/ KrankenhausbehandlungPflegebeduerftige.html (accessed March 2018).

8. Ruscher C, Schaumann R, Mielke M. Herausforderungen durch Infektionen und mehrfach-resistente Bakterien bei alten Menschen in Heimen. Bundesgesundheitsblatt Gesundheitsforschung Gesundheitsschutz 2012;55:1444-52.

9. Peters C, Dulon M, Kleinmüller O, et al. MRSA prevalence and risk factors among health personnel and residents in nursing homes in Hamburg, Germany - a cross-sectional study. PLoS One 2017;12:e0169425.

10. Harmsen D, Claus $H$, Witte $W$, et al. Typing of methicillin-resistant Staphylococcus aureus in a university hospital setting by using novel software for spa repeat determination and database management. $J$ Clin Microbiol 2003;41:5442-8.

11. Neumann N, Mischler D, Cuny C, et al. [Multidrug-resistant organisms (MDRO) in patients in outpatient care in the RhineMain region, Germany, in 2014: prevalence and risk factors]. Bundesgesundheitsblatt Gesundheitsforschung Gesundheitsschutz 2016;59:292-300.

12. Gruber I, Heudorf U, Werner G, et al. Multidrug-resistant bacteria in geriatric clinics, nursing homes, and ambulant care--prevalence and risk factors. Int J Med Microbiol 2013;303:405-9.

13. Hübner NO, Dittmann K, Begunk R, et al. Infection control measures and prevalence of multidrug-resistant organisms in non-hospital care settings in northeastern Germany: results from a one-day point prevalence study. J Hosp Infect 2017;97:234-40.

14. Immergluck LC, Satola SW, Jain S, et al. Methicillin-resistant Staphylococcus aureus colonization among pediatric health care 
workers from different outpatient settings. Am J Infect Control 2013;41:841-3.

15. Spegel $\mathrm{H}$, Höller $\mathrm{C}$, Randzio O, et al. [Infection control management and practice in home care - analysis of structure quality]. Gesundheitswesen 2013;75:111-8.

16. Raupach-Rosin H, Rübsamen N, Szkopek S, et al. Care for MRSA carriers in the outpatient sector: a survey among MRSA carriers and physicians in two regions in Germany. BMC Infect Dis 2016;16:184.
17. Adler AC, Spegel H, Wilke J, et al. [Strategies to prevent the transmission of multidrug-resistant pathogens and their practical implementation in oupatient care]. Gesundheitswesen 2012;74:653-60.

18. Peters $\mathrm{C}$, Schablon A, Bollongino $\mathrm{K}$, et al. Multiresistant pathogens in geriatric nursing - infection control in residential facilities for geriatric nursing in Germany. GMS Hyg Infect Control 2014;9:Doc22. 